\title{
Evaluation of Coloured and White Rice Genotypes for Yield and Quality
}

\author{
Kumar Saurabh Singh ${ }^{*}$, Y. Suneetha ${ }^{2}$, G. Vinay Kumar ${ }^{3}$, V. Srinivasa Rao ${ }^{4}$, \\ D. Sandeep Raja ${ }^{5}$ and T. Srinivas ${ }^{1}$
}

${ }^{1}$ Department of Genetics and Plant Breeding, ${ }^{2}$ Agricultural Research Station, ${ }^{3}$ Agricultural College Farm, ${ }^{4}$ Department of Statistics and Computer Applications and ${ }^{5}$ Post Harvest Technology Centre, Agricultural College, Bapatla, India

*Corresponding author

\section{A B S T R A C T}

\begin{tabular}{|l|}
\hline K e y w o r d s \\
Coloured Rice, \\
Grain Yield, Mean \\
performance and \\
Nutritional Quality
\end{tabular}

The present investigation was undertaken with 33 coloured and white rice genotypes to identify promising slender grain genotypes with high yield and good nutrition quality. The study involved seven red pericarp, eight black pericarp and 17 white rice genotypes, in addition to the check, BPT 5204. The results revealed black pericarp genotypes to be in general, high yielding with intermediate amylose content, high phenol, protein, zinc and iron content, compared to the red pericarp and white rice genotypes studied in the present investigation. The red pericarp genotypes were in general noticed to be early with high antioxidant activity, compared to the black pericarp and white rice genotypes. The white rice genotypes, however, recorded higher head rice recovery per cent, compared to the red and black pericarp genotypes. Further, the red pericarp genotype, BPT 3178; black pericarp genotype, BPT 2848; and the white rice genotypes, BPT 2615, BPT 2782 and MTU 1281 were identified to be promising high yielding and nutritionally rich rice genotypes, compared to BPT 5204.

\section{Introduction}

Rice is a major source of food for about three million people worldwide and accounts for about 20 per cent of calorie consumption. In Asia, nearly two billion people depend on rice for their 60-70 percent calories. Increased health consciousness among the rice consumers in the recent years has resulted in greater attention to rice genotypes containing higher levels of bioactive compounds, such as antioxidants. In this context, rice genotypes with red and black pericarp color containing high levels of antioxidants (Tian et al., 2004) are in increasing demand. The present investigation is therefore, an attempt to identify slender grain colored rice genotypes, superior to BPT 5204, the popular rice variety, in terms of grain yield and nutritional quality, namely, level of antioxidants, zinc, iron and protein content.

\section{Materials and Methods}

The experimental material consisted of 33 white and coloured rice genotypes obtained from Agricultural Research Station, Bapatla, Andhra Pradesh state in addition to 
collections from Telangana and Tamil Nadu states. Among the 33 genotypes, 15 genotypes were coloured, of which, seven were with red pericarp and eight genotypes were with black pericarp, while remaining 18 genotypes had brown pericarp and were white rice genotypes including, BPT 5204, a popular high yielding white rice genotype with excellent cooking quality traits, which was used as check variety in the present study. Details of the genotypes studied in the present investigation are presented in Table 1 and Plates 1-2.

All the 33 genotypes were sown at Agricultural College Farm, Bapatla during Kharif 2019 on separate raised nursery beds. All recommended package of practices were adopted to raise a healthy nursery and thirty days old seedlings were transplanted in the main field laid out in Randomized Block Design (RBD) with three replications. Each genotype was transplanted separately in 5 rows of $4.5 \mathrm{~m}$ length by adopting a spacing of $20 \mathrm{~cm}$ between rows and $15 \mathrm{~cm}$ between plants. All the recommended package of practices were adopted throughout the crop growth period and need based plant protection measures were taken up to raise a healthy crop. Observations were recorded on five randomly selected plants for grain yield per plant; days to 50 per cent flowering; and the quality characters, namely, head rice recovery per cent, amylose content, alkali spreading value, protein content, total phenol content, total antioxidant activity, zinc and iron content in addition to grain type were recorded.

However, days to 50 per cent flowering was recorded on plot basis. In contrast, observations for the quality traits studied were obtained from a random grain sample drawn from each plot in each genotype and replication using standard procedures. The data collected was subjected to standard statistical procedures given by Panse and Sukhatme (1967).

\section{Results and Discussion}

The analysis of variance (ANOVA) for yield and quality characters studied in the present investigation is presented in Table 2. A perusal of the results revealed significant differences among the genotypes for all the characters studied, indicating the existence of sufficient variation among the genotypes studied.

Mean performance of the genotypes studied for yield, days to 50 per cent flowering and quality characters are presented in Table 3 and Fig.1. Grain yield per plant in the present study was observed to range from $11.00 \mathrm{~g}$ (BPT 2507) to 33.41g (Hallabhatta) with an overall mean value of $21.91 \mathrm{~g}$, indicating high variability among the genotypes with respect to grain yield. The findings are in agreement with the reports of Nagadurga Rao (2019). Among the black pericarp genotypes, BPT 3141 (18.66g) recorded minimum grain yield per plant, while BPT 3165 recorded maximum grain yield per plant $(29.33 \mathrm{~g})$.

Grain yield per plant among the red pericarp genotypes was noticed to range from $16.00 \mathrm{~g}$ (Chittiga) to 33.41g (Hallabhatta); and from $11.00 \mathrm{~g}$ (BPT 2507) to 32.04g (BPT 2615) among the white rice genotypes. A perusal of the results also revealed significantly higher grain yield per plant, compared to the check, BPT $5204(17.00 \mathrm{~g})$ for five red pericarp genotypes, namely, Apputhokal, Asandi, BPT 3111, BPT 3178 and Hallabhatta; six black pericarp genotypes, namely, BPT 2841, BPT 2848, BPT 3136, BPT 3145, BPT 3165 and Kakirekalu; and six white rice genotypes, namely, BPT 2615, BPT 2776, BPT 2782, BPT 3173, MTU 1281 and US 301. The red $(23.64 \mathrm{~g})$ and black (24.16g) pericarp genotypes studied in the present investigation had in general recorded higher grain yield per plant, compared to the white rice genotypes (20.21g) studied in the present investigation. 
The findings are in conformity with the reports of Sridevi (2018).

Days to 50 per cent flowering in the present study was observed to range from 95 (Asandi) to 120 days (BPT 2660) with an overall mean of 110 days. Further, early flowering of the red (104 days) and black pericarp genotypes (109 days) was observed in the present study, compared to the white rice genotypes (112 days). The findings are in agreement with the reports of Sridevi (2018). Among the red rice genotypes, Asandi (95 days) recorded minimum days to 50 per cent flowering, while BPT 3139 recorded maximum number of days to 50 per cent flowering (118 days). Days to 50 per cent flowering among the black pericarp genotypes was noticed to range from 96 days (Kakirekalu) to 117 days (BPT 3141); and from 103 days (ADT 49) to 120 days (BPT 2660) among the white rice genotypes.

Head rice recovery was noticed to range from 42.33 per cent (Chittiga) to 69.40 per cent (BPT 2660). Overall average head rice recovery of the genotypes studied in the present investigation was 59.83 per cent. In general, the white rice genotypes recorded higher head rice recovery percentage (63.12\%), compared to black pericarp $(56.50 \%)$ and red pericarp $(55.15 \%)$ genotypes. Among the white rice genotypes, BPT 2776 (56.15\%) recorded minimum head rice recovery percentage, while BPT 2660 recorded maximum head rice recovery percentage (69.40\%). Among the black pericarp genotypes, head rice recovery percentage was noticed to range from 50.83 (BPT 2841) to 68.50 per cent (BPT 2848); and from 42.33 (Chittiga) to 64.33 per cent (BPT 3111) among the red pericarp genotypes. Further, none of the genotypes studied had recorded significantly greater head rice recovery per cent, compared to the check, BPT $5204(65.50 \%)$ in the present investigation. However, BPT 3111 and BPT 3178 red pericarp genotypes; BPT 2848 black pericarp genotype; and 12 white rice genotypes, namely, BPT 2507, BPT 2595, BPT 2615, BPT 2660, BPT 2782, BPT 3173, JKRH 3333, MTU 1281, US 301, WGL 14 and $27 \mathrm{P} 63$ had recorded head rice recovery per cent on par with BPT 5204.

Amylose content of milled rice has been found to be positively correlated with hardness values of cooked rice and negatively with stickiness values. Amylose content determines the texture of cooked rice and rice varieties with amylose content between 20-25 are considered as intermediate which cook as fluffy and flaky (Sridevi, 2018). In the present study, amylose content was noticed to range from 17.53 (BPT 3173) to 30.32 per cent (BPT 2766) with an overall mean value of 22.63 per cent. In general, the red pericarp genotypes recorded higher amylose content percentage $(23.76 \%)$, compared to black pericarp $(21.50 \%)$ and white rice $(22.68 \%)$ genotypes. Among the red pericarp genotypes, Chittiga $(21.75 \%)$ recorded minimum amylose content, while BPT 3111 recorded maximum amylose content (25.22\%). Among the black pericarp genotypes, amylose content was noticed to range from 19.52 (Kakirekalu) to 24.39 per cent (BPT 2841); and from 17.53 (BPT 3173) to 30.32 per cent (BPT 2766) among the white rice genotypes. Further, all red pericarp genotypes studied; all black pericarp genotypes studied, except Kakirekalu; and all white rice genotypes studied, except, ADT 49, BPT 2660, BPT 2766, BPT 3173, US 301 and 27 P 63 were noticed to have intermediate amylose content of 20-25 per cent desired by the rice consumers of the state of Andhra Pradesh.

Rice genotypes with intermediate alkali spreading value (4-5) are desirable. However, alkali spreading value of the genotypes 
studied in the present investigation was observed to range from 2.50 (MTU 1281) to 7.00 (BPT 3173 and BPT 2776) with an overall mean value of 4.17. In general, the white rice genotypes recorded higher ASV (4.27), compared to black pericarp (4.06) and red pericarp (4.00) genotypes. Among the white rice genotypes, MTU 1281 (2.50) recorded minimum ASV, while BPT 3173 and BPT 2776 recorded maximum ASV (7.00). Among the black pericarp genotypes, ASV was noticed to range from 3.00 (BPT 3141 ) to 5.16 (BPT 2841); and from 3.22 (BPT 3139) to 5.00 (BPT 3178 and Hallabhatta) among the red pericarp genotypes. Further, intermediate ASV (4.00 5.00) was noticed for the red pericarp genotypes, namely, Apputhokal, BPT 3178 and Hallabhatta; black pericarp genotypes, namely, BPT 2848, BPT 3145 and BPT 3165; and six white rice genotypes, namely, BPT 2411, BPT 2595, BPT 2782, BPT 2846, BPT 5204 and US 301.

Protein being the second dominant component of rice grain after starch, its content and amino acid composition will determine the nutritional quality of rice. Based on protein content, rice varieties are classified into high $(>12 \%)$, medium $(9-12 \%)$ and low $(<9 \%)$ as suggested by Meijuam and Samuel (2005). The protein per cent of genotypes studied in the present investigations was observed to range from 6.80 (MTU 1281) to 13.50 per cent (Kakirekalu) with an overall mean value of 9.45 per cent. In general, the black $(12.09 \%)$ and red pericarp (10.60\%) genotypes had recorded higher protein content, compared to white rice $(7.82 \%)$ genotypes. Similarly, Raghuvanshi et al., (2017) earlier reported that the red rice genotypes had higher amount of protein content, when compared with white rice genotypes. They also suggested that the nutritional quality of red rice was comparable to many millets, fruits and vegetables. Pathak et al., (2017) also reported that pigmented rice had higher amount of protein content than non-pigmented rice, similar to the findings of the present study. Among the black pericarp genotypes, BPT $3140(10.35 \%)$ recorded minimum protein content, while Kakirekalu recorded maximum protein content $(13.50 \%)$. Further, the three black pericarp genotypes, namely, BPT 2848 (12.85\%), BPT 3136 $(12.50 \%)$ and Kakirekalu (13.50\%) only had recorded high protein content $(>12.0 \%)$ among the 33 genotypes studied in the present investigation. Among the red pericarp genotypes, protein content was noticed to range from 8.20 (BPT 3139) to 11.50 per cent (Chittiga); and from 6.80 (MTU 1281) to 10.00 per cent (BPT 2660) among the white rice genotypes. A perusal of the results revealed significantly greater protein content, compared to the check, BPT 5204 (8.40\%) for all red pericarp genotypes studied, except, BPT 3139; all black pericarp genotypes studied; and BPT 2595 white rice genotype.

A perusal of the results on total phenol content of the genotypes studied in the present investigation revealed the trait to range from $39.52 \mathrm{mg}$ (BPT 2615) to $267.13 \mathrm{mg}$ (Kakirekalu) with an overall average value of $90.56 \mathrm{mg}$, indicating wide range of variation. The phenolic compounds are mainly associated with the pericarp in rice and the grains with darker pericarp colour such as red and black contain higher amount of polyphenols (Itani, 2004). The concentration of total phenolics in the grain has been positively associated with antioxidant activity Itani et al., 2002) with potential beneficial effects on health such as reduction of oxidative stress (Hu et al., 2003). Hence, highest amount of phenolic compounds is a desirable trait and the coloured rice genotypes (black and red) studied in the present investigation were observed to contain high amount of phenolic compounds than white rice genotypes evaluated. In general, the black 
pericarp genotypes had recorded higher total phenol content $(156.16 \mathrm{mg})$, compared to red pericarp $(96.41 \mathrm{mg}$ ) and white rice $(59.13 \mathrm{mg})$ genotypes. Among the black pericarp genotypes, BPT $3136(82.69 \mathrm{mg})$ recorded minimum total phenol content, while Kakirekalu recorded maximum total phenol content (267.13mg). Among the red pericarp genotypes, total phenol content was noticed to range from $82.00 \mathrm{mg}$ (Hallabhatta) to $114.84 \mathrm{mg}$ (Apputhokal); and from $39.52 \mathrm{mg}$ (BPT 2615) to $80.90 \mathrm{mg}$ (BPT 3173) among the white rice genotypes. A perusal of the results revealed significantly greater total phenol content, compared to the check, BPT $5204(53.83 \mathrm{mg})$ for all red and black pericarp genotypes studied; and six white rice genotypes, namely, ADT 49, BPT 2660, BPT 2766, BPT 2782, BPT 3173, PHI 17108 and 27 P 63. Irkali et al., (2012) also reported that total phenol content was more in black and red rice than non pigmented rice. Chakuton et al., (2012), Saikia et al., (2012) and Pathak et al., (2017) also reported that pigmented rice had higher amount of total phenol content than non pigmented rice.

In the present study, the white coloured genotype, BPT 2595, recorded minimum value for total antioxidant activity $(25.68 \mathrm{mg}$ ), while maximum value was manifested by the red coloured genotype, Apputhokal (109.73 $\mathrm{mg}$ ). Overall average value of the genotypes studied in the present investigation was $62.32 \mathrm{mg}$. In general, the red $(96.62 \mathrm{mg})$ and black pericarp (90.63mg) genotypes had recorded higher total antioxidant activity, compared to white rice $(36.38 \mathrm{mg})$ genotypes. The findings are in conformity with the reports of Tian et al., (2004). Coloured rice was reported to have a health promoting potential due to its instantial antioxidant activity which inhibits the formation or reduces the concentration of reactive cell damaging free radicals thus protecting the body tissues from oxidative damage. Among the red pericarp genotypes, Chittiga (76.25mg) recorded minimum total antioxidant activity, while Apputhokal recorded maximum total antioxidant activity (109.73mg). Among the black pericarp genotypes, total antioxidant activity was noticed to range from $74.39 \mathrm{mg}$ (BPT 3165 ) to $103.87 \mathrm{mg}$ (BPT 3141); and from $25.68 \mathrm{mg}$ (BPT 2595) to 47.07 per cent (BPT 3173) among the white rice genotypes. A perusal of the results revealed significantly greater total antioxidant activity, compared to the check, BPT 5204 (29.92mg) for all red and black pericarp genotypes studied; and eight white rice genotypes, namely, BPT 2660, BPT 2782, BPT 2846, BPT 3173, JKRH 3333, PHI 17108, MTU 1281 and 27 P 63. Raghuvanshi et al., (2017) also reported that red pericarp coloured rice genotypes showed excellent antioxidant properties which are in agreement with the present results. Chakuton et al., (2012), Veni et al. (2016) and Pathak et al. (2017) also reported that the pigmented rice was found to have highest total antioxidant activity than non pigmented rice.

Zinc content of the genotypes studied in the present investigation ranged from $12.15 \mathrm{ppm}$ (ADT 49) to 30.16ppm (BPT 3136) with an overall mean of 20.88ppm. In general, the black pericarp genotypes recorded higher Zinc content (27.78ppm), compared to red pericarp (24.87ppm) and white rice (16.27ppm) genotypes. Similar results were reported earlier by Sridevi (2018) for zinc content in red and black coloured genotypes, compared to white rice genotypes. Pathak et al., (2017) and Laenoia et al., (2015) also reported that pigmented rice was found to have high amount of zinc content than non pigmented rice. Among the black pericarp genotypes, BPT 2848 (24.81ppm) recorded minimum zinc content, while BPT 3136 recorded maximum zinc content (30.16ppm). Among the red pericarp genotypes, zinc content was noticed to range from 22.16ppm 
(Hallabhatta) to 27.16ppm (BPT 3139); and from 12.15ppm (ADT 49) to 19.50ppm (JKRH 3333) among the white rice genotypes. A perusal of the results revealed significantly greater zinc content, compared to the check, BPT 5204 (16.50ppm) for all red and black pericarp genotypes studied; and four white rice genotypes, namely, BPT 2660 , BPT 2776, BPT 2782 and JKRH 3333.

Table.1 Details of the rice genotypes studied in the present investigation

\begin{tabular}{|c|c|c|c|}
\hline S.No. & Genotype & Cross combination/ Pedigree & Origin \\
\hline \multicolumn{4}{|c|}{ Red pericarp genotypes } \\
\hline 1. & Apputhokal & Landraces & Telangana \\
\hline 2. & Asandi & Landraces & Telangana \\
\hline 3. & Chittiga & Landraces & Telangana \\
\hline 4. & BPT 3111 & Swarna/ IRGC 18195// MTU 1081 & Andhra Pradesh \\
\hline 5. & BPT 3139 & Cult. $01120305 /$ cult. $0910025-7$ & Andhra Pradesh \\
\hline 6. & BPT 3178 & Cult. $01120305 /$ cult. $0910025-7$ & Andhra Pradesh \\
\hline 7. & Hallabhatta & Landraces & Telangana \\
\hline \multicolumn{4}{|c|}{ Black pericarp genotypes } \\
\hline 8. & BPT 2841 & MTU 7029/IRGC 18195/MTU 1081 & Andhra Pradesh \\
\hline 9. & BPT 2848 & RP Bio 226*1/1RGC 48493 & Andhra Pradesh \\
\hline 10. & BPT 3136 & RP Bio 226*1/1RGC 18195 & Andhra Pradesh \\
\hline 11. & BPT 3140 & Swarna/1RGC 18195 /MTU 1081 & Andhra Pradesh \\
\hline 12. & BPT 3141 & RP Bio 226*1/ 1RGC 30938 & Andhra Pradesh \\
\hline 13. & BPT 3145 & RP Bio 226/ IRGC26940// MTU 1081 & Andhra Pradesh \\
\hline 14. & BPT 3165 & BPT 3291/BPT 2411 & Andhra Pradesh \\
\hline 15. & Kakirekalu & Landraces & Telangana \\
\hline \multicolumn{4}{|c|}{ ericarp white rice genotypes } \\
\hline 16. & ADT 49 & CR 1009/Jeeragasambha & Tamil Nadu \\
\hline 17. & BPT 2411 & BPT 5204/BPT 4358 & Andhra Pradesh \\
\hline 18. & BPT 2507 & ВPT 1235/BPT 5204//BPT 5204 & Andhra Pradesh \\
\hline 19. & BPT 2595 & Mutant of BPT 2270 & Andhra Pradesh \\
\hline 20. & BPT 2615 & IR 8/Tulasi & Andhra Pradesh \\
\hline 21. & BPT 2660 & BPT 1768/ NLR 145 & Andhra Pradesh \\
\hline 22. & BPT 2766 & BPT 2270/NLR 145 & Andhra Pradesh \\
\hline 23. & BPT 2776 & BPT 2231/ NLR 145 & Andhra Pradesh \\
\hline 24. & BPT 2782 & NLR 145/ MTU 2077 & Andhra Pradesh \\
\hline 25. & BPT 2846 & MTU 1061/IR 78585-64-2-4-3-1 & Andhra Pradesh \\
\hline 26. & BPT 3173 & BPT 3291/JGL 3844 & Andhra Pradesh \\
\hline 27. & BPT 5204 & GEB24/TN1/ Mahsuri & Andhra Pradesh \\
\hline 28. & JKRH 3333 & Pvt. Research Hybrid & Telangana \\
\hline 29. & PHI 17108 & Pvt. Research Hybrid & Telangana \\
\hline 30. & WGL 14 & BPT 5204/ARC 5984//BPT 3291 & Andhra Pradesh \\
\hline 31. & MTU 1281 & MTU 1075/MTU 1081/MTU 1121 & Andhra Pradesh \\
\hline 32. & 27 P 63 & Pvt. Research Hybrid & Telangana \\
\hline 33. & US 301 & Pvt. Research Hybrid & Telangana \\
\hline
\end{tabular}


Table.2 Analysis of variance for yield and quality characters in rice

\begin{tabular}{|l|l|c|c|c|c|c|c|c|c|c|c|c|c|}
\hline $\begin{array}{l}\text { Source of } \\
\text { variation }\end{array}$ & d.f. & $\begin{array}{c}\text { Grain } \\
\text { yield per } \\
\text { plant }\end{array}$ & $\begin{array}{c}\text { Days to 50 Head Rice } \\
\text { per cent } \\
\text { flowering }\end{array}$ & $\begin{array}{c}\text { Amylose } \\
\text { Recovery }\end{array}$ & $\begin{array}{c}\text { Alkali } \\
\text { Content } \\
\text { Spreading } \\
\text { Value }\end{array}$ & $\begin{array}{c}\text { Protein } \\
\text { Content }\end{array}$ & $\begin{array}{c}\text { Total } \\
\text { Phenol } \\
\text { Content }\end{array}$ & $\begin{array}{c}\text { Total } \\
\text { Antioxidant } \\
\text { Activity }\end{array}$ & $\begin{array}{c}\text { Zinc } \\
\text { content }\end{array}$ & $\begin{array}{c}\text { Iron } \\
\text { content }\end{array}$ \\
\hline Replications & 2 & 9.11 & 52.16 & 15.98 & 1.93 & 0.050 & 0.13 & 21.78 & 47.27 & 2.89 & 2.71 \\
\hline Genotypes & 32 & $99.61 * *$ & $133.54^{* *}$ & $118.60^{* *}$ & $18.55^{* *}$ & $3.77 * *$ & $13.12^{* *}$ & $7154.33^{* *}$ & $2709.38^{* *}$ & $95.66^{* *}$ & $25.74 * *$ \\
\hline Error & 64 & 5.22 & 13.32 & 6.16 & 0.56 & 0.13 & 0.10 & 18.58 & 15.74 & 1.23 & 0.96 \\
\hline
\end{tabular}

** Significant at 1 per cent level of probability

Table.3 Mean performance of the genotypes studied for yield and quality characters in rice

\begin{tabular}{|c|c|c|c|c|c|c|c|c|c|c|c|}
\hline $\begin{array}{l}\text { S. } \\
\text { No. }\end{array}$ & Genotypes & $\begin{array}{c}\text { Grain } \\
\text { yield } \\
\text { per plant } \\
\text { (g) }\end{array}$ & $\begin{array}{l}\text { Days to } 50 \\
\text { per cent } \\
\text { flowering }\end{array}$ & $\begin{array}{c}\text { Head Rice } \\
\text { Recovery } \\
(\%)\end{array}$ & $\begin{array}{c}\text { Amylose } \\
\text { Content } \\
(\%)\end{array}$ & $\begin{array}{c}\text { Alkali } \\
\text { Spreading } \\
\text { Value }\end{array}$ & $\begin{array}{l}\text { Protein } \\
\text { Content } \\
(\%)\end{array}$ & $\begin{array}{c}\text { Total } \\
\text { Phenol } \\
\text { Content } \\
(\mathrm{mg} / \mathbf{1 0 0 g})\end{array}$ & $\begin{array}{c}\text { Total } \\
\text { Antioxidant } \\
\text { Activity } \\
\text { (mgAAE/100g) }\end{array}$ & $\begin{array}{c}\text { Zinc } \\
\text { content } \\
\text { (ppm) }\end{array}$ & $\begin{array}{c}\text { Iron } \\
\text { content } \\
\text { (ppm) }\end{array}$ \\
\hline \multicolumn{12}{|c|}{ Red pericarp genotypes } \\
\hline 1. & Apputhokal & 24.03 & 98 & 56.68 & 23.43 & 4.50 & 10.90 & 114.84 & 109.73 & 23.66 & 10.93 \\
\hline 2. & Asandi & 23.38 & 95 & 47.66 & 23.88 & 3.50 & 10.75 & 87.59 & 95.49 & 25.46 & 11.68 \\
\hline 3. & BPT 3111 & 23.25 & 107 & 64.33 & 25.22 & 3.88 & 11.16 & 92.70 & 91.57 & 27.00 & 13.08 \\
\hline 4. & BPT 3139 & 18.00 & 118 & 59.33 & 23.11 & 3.22 & 8.20 & 87.54 & 101.41 & 27.16 & 13.33 \\
\hline 5. & BPT 3178 & 27.43 & 115 & 61.59 & 24.9 & 5.00 & 10.92 & 97.58 & 106.49 & 23.01 & 10.76 \\
\hline 6. & Chittiga & 16.00 & 98 & 42.33 & 21.75 & 3.33 & 11.50 & 112.68 & 76.25 & 25.66 & 12.33 \\
\hline 7. & Hallabhatta & 33.41 & 100 & 54.16 & 24.03 & 5.00 & 10.80 & 82.00 & 95.46 & 22.16 & 10.83 \\
\hline \multicolumn{2}{|r|}{ Range- Min. } & 16.00 & 95 & 42.33 & 21.75 & 3.22 & 8.20 & 82.00 & 76.25 & 22.16 & 10.76 \\
\hline \multicolumn{2}{|c|}{-Max. } & 33.41 & 118 & 64.33 & 25.22 & 5.00 & 11.50 & 114.84 & 109.73 & 27.16 & 13.33 \\
\hline \multicolumn{2}{|c|}{ Mean } & 26.64 & 104 & 55.15 & 23.76 & 4.00 & 10.60 & 96.41 & 96.62 & 24.87 & 11.84 \\
\hline \multicolumn{12}{|c|}{ Black pericarp genotypes } \\
\hline 1. & BPT 2841 & 24.97 & 105 & 50.83 & 24.39 & 5.16 & 11.83 & 152.62 & 96.58 & 26.16 & 13.00 \\
\hline 2. & BPT 2848 & 25.00 & 112 & 68.50 & 20.72 & 4.11 & 12.85 & 134.29 & 91.22 & 24.81 & 12.33 \\
\hline 3. & BPT 3136 & 28.93 & 111 & 55.34 & 21.90 & 3.88 & 12.50 & 82.69 & 77.90 & 30.16 & 15.16 \\
\hline
\end{tabular}




\begin{tabular}{|c|c|c|c|c|c|c|c|c|c|c|c|}
\hline 4. & BPT 3140 & 20.33 & 111 & 58.69 & 22.72 & 3.61 & 10.35 & 200.22 & 102.88 & 26.41 & 13.21 \\
\hline 5. & BPT 3141 & 18.66 & 117 & 60.91 & 20.58 & 3.00 & 13.00 & 146.10 & 103.87 & 27.98 & 14.32 \\
\hline 6. & BPT 3145 & 22.33 & 110 & 52.78 & 21.69 & 4.38 & 12.00 & 127.99 & 93.00 & 28.89 & 14.41 \\
\hline 7. & BPT 3165 & 29.33 & 109 & 54.16 & 20.55 & 4.94 & 10.74 & 138.28 & 74.39 & 29.83 & 19.25 \\
\hline 8. & Kakirekalu & 23.80 & 96 & 51.00 & 19.52 & 3.44 & 13.50 & 267.13 & 85.22 & 28.00 & 14.66 \\
\hline & Range-Min. & 18.66 & 96 & 50.83 & 19.52 & 3.00 & 10.35 & 82.69 & 74.39 & 24.81 & 12.33 \\
\hline & -Max. & 29.33 & 117 & 68.50 & 24.39 & 5.16 & 13.50 & 267.13 & 103.87 & 30.16 & 19.25 \\
\hline & Mean & 24.16 & 109 & 56.50 & 21.50 & 4.06 & 12.09 & 156.16 & 90.63 & 27.78 & 14.54 \\
\hline \multicolumn{12}{|c|}{ Brown pericarp white rice genotypes } \\
\hline 1. & ADT 49 & 19.66 & 103 & 61.41 & 25.60 & 5.33 & 7.65 & 66.99 & 32.00 & 12.15 & 6.93 \\
\hline 2. & BPT 2411 & 18.74 & 118 & 61.22 & 20.52 & 4.00 & 7.23 & 54.32 & 30.32 & 16.50 & 8.16 \\
\hline 3. & BPT 2507 & 11.00 & 109 & 62.00 & 22.63 & 2.55 & 8.10 & 56.43 & 35.75 & 14.74 & 8.66 \\
\hline 4. & BPT 2595 & 18.00 & 117 & 63.33 & 23.55 & 4.44 & 9.76 & 56.33 & 25.68 & 17.28 & 8.56 \\
\hline 5. & BPT 2615 & 32.04 & 107 & 64.23 & 22.32 & 2.94 & 8.15 & 39.52 & 33.21 & 14.90 & 7.43 \\
\hline 6. & BPT 2660 & 20.93 & 120 & 69.40 & 25.88 & 2.88 & 10.00 & 64.07 & 40.81 & 19.16 & 9.46 \\
\hline 7. & BPT 2766 & 20.83 & 116 & 60.79 & 30.32 & 5.16 & 6.90 & 66.23 & 32.32 & 17.33 & 8.60 \\
\hline 8. & BPT 2776 & 23.00 & 119 & 56.15 & 22.90 & 7.00 & 7.00 & 49.66 & 36.04 & 18.65 & 9.20 \\
\hline 9. & BPT 2782 & 28.50 & 113 & 63.60 & 21.64 & 4.16 & 7.50 & 70.06 & 39.30 & 19.12 & 9.43 \\
\hline 10. & BPT 2846 & 14.16 & 116 & 60.54 & 22.40 & 4.16 & 7.25 & 58.49 & 37.87 & 12.75 & 6.46 \\
\hline 11. & BPT 3173 & 28.69 & 110 & 61.73 & 17.53 & 7.00 & 7.90 & 80.90 & 47.07 & 15.83 & 7.92 \\
\hline 12. & BPT 5204 & 17.00 & 110 & 65.5 & 24.80 & 4.00 & 8.40 & 53.83 & 29.92 & 16.50 & 9.30 \\
\hline 13. & JKRH 3333 & 12.00 & 107 & 67.60 & 21.89 & 6.00 & 7.90 & 55.09 & 43.32 & 19.50 & 10.46 \\
\hline 14. & PHI 17108 & 20.33 & 109 & 57.72 & 22.61 & 3.00 & 7.31 & 64.41 & 45.00 & 17.5 & 10.16 \\
\hline 15. & MTU 1281 & 27.80 & 111 & 69.12 & 21.29 & 2.50 & 6.80 & 57.53 & 42.00 & 17.78 & 9.63 \\
\hline 16. & US 301 & 23.66 & 106 & 65.66 & 17.90 & 4.55 & 7.50 & 46.43 & 32.63 & 12.61 & 7.13 \\
\hline 17. & WGL 14 & 14.50 & 108 & 62.83 & 24.91 & 3.33 & 8.25 & 58.62 & 31.00 & 17.66 & 9.53 \\
\hline 18. & 27 P 63 & 13.00 & 110 & 63.33 & 19.67 & 3.88 & 7.30 & 65.44 & 40.61 & 12.95 & 7.20 \\
\hline \multicolumn{2}{|r|}{ Range-Min. } & 11.00 & 103 & 56.15 & 17.53 & 2.50 & 6.80 & 39.52 & 25.68 & 12.15 & 6.46 \\
\hline \multicolumn{2}{|r|}{-Max. } & 32.04 & 120 & 69.40 & 30.32 & 7.00 & 10.00 & 80.90 & 47.07 & 19.50 & 10.46 \\
\hline \multicolumn{2}{|c|}{ Mean } & 20.21 & 112 & 63.12 & 22.68 & 4.27 & 7.82 & 59.13 & 36.38 & 16.27 & 8.56 \\
\hline \multicolumn{2}{|c|}{ Overall Range-Min. } & 11.00 & 95 & 42.33 & 17.53 & 2.50 & 6.80 & 39.52 & 25.68 & 12.15 & 6.46 \\
\hline \multicolumn{2}{|c|}{-Max. } & 33.41 & 120 & 69.40 & 30.32 & 7.00 & 13.50 & 267.13 & 109.13 & 30.16 & 19.25 \\
\hline \multicolumn{2}{|r|}{ Mean } & 21.91 & 110 & 59.83 & 22.63 & 4.17 & 9.45 & 90.56 & 62.32 & 20.88 & 10.71 \\
\hline \multicolumn{2}{|r|}{ SEM } & 1.32 & 2.10 & 1.43 & 0.43 & 0.21 & 0.19 & 2.48 & 2.29 & 0.64 & 0.56 \\
\hline \multicolumn{2}{|r|}{ C.D. (0.05) } & 3.72 & 5.95 & 4.05 & 1.23 & 0.59 & 0.53 & 7.03 & 6.47 & 1.81 & 1.60 \\
\hline
\end{tabular}


Table.4 Details of the promising slender grain genotypes identified in the present study

\begin{tabular}{|c|c|c|c|c|c|c|c|c|c|c|}
\hline S. No. & Genotypes & $\begin{array}{l}\text { Grain yield } \\
\text { per plant (g) }\end{array}$ & $\begin{array}{c}\text { Per cent increase } \\
\text { in yield over } \\
\text { BPT } 5204\end{array}$ & $\begin{array}{c}\text { Grain } \\
\text { type }\end{array}$ & Duration & $\begin{array}{c}\text { Head } \\
\text { rice } \\
\text { recovery } \\
(\%)\end{array}$ & $\begin{array}{c}\text { Protein } \\
\text { content }(\%)\end{array}$ & $\begin{array}{c}\text { Total Antioxidant } \\
\text { Activity } \\
\text { (mg AAE/100g) }\end{array}$ & $\begin{array}{c}\text { Zinc } \\
\text { content } \\
\text { (ppm) }\end{array}$ & $\begin{array}{c}\text { Iron } \\
\text { content } \\
\text { (ppm) }\end{array}$ \\
\hline \multicolumn{11}{|c|}{ Red pericarp } \\
\hline 1. & BPT 3178 & 27.43 & 61.35 & LS & Mid-late & 61.59 & 10.92 & 106.49 & 25.66 & 10.76 \\
\hline \multicolumn{11}{|c|}{ Black pericarp } \\
\hline 2. & BPT 2848 & 25.00 & 47.05 & MS & Mid-late & 68.50 & 12.85 & 91.22 & 24.81 & 12.33 \\
\hline \multicolumn{11}{|c|}{ Brown pericarp white rice genotypes } \\
\hline 3. & BPT 2615 & 32.04 & 88.47 & MS & Medium & 64.23 & 8.15 & 33.21 & 14.90 & 7.43 \\
\hline 4. & BPT 2782 & 28.50 & 67.64 & MS & Mid-late & 63.60 & 7.50 & 39.30 & 19.12 & 9.43 \\
\hline 5. & MTU 1281 & 27.80 & 63.52 & MS & Medium & 69.12 & 6.80 & 42.00 & 17.78 & 9.63 \\
\hline \multicolumn{11}{|c|}{ Check variety } \\
\hline 1. & BPT 5204 & 17.00 & _ & MS & Mid-late & 65.50 & 8.40 & 29.92 & 16.50 & 9.30 \\
\hline \multicolumn{2}{|c|}{ C.D (0.05) } & 3.72 & - & - & 7.32 & 4.05 & & 0.53 & 1.81 & 1.60 \\
\hline
\end{tabular}


Fig.1 Mean performance of the genotypes for yield and quality characters

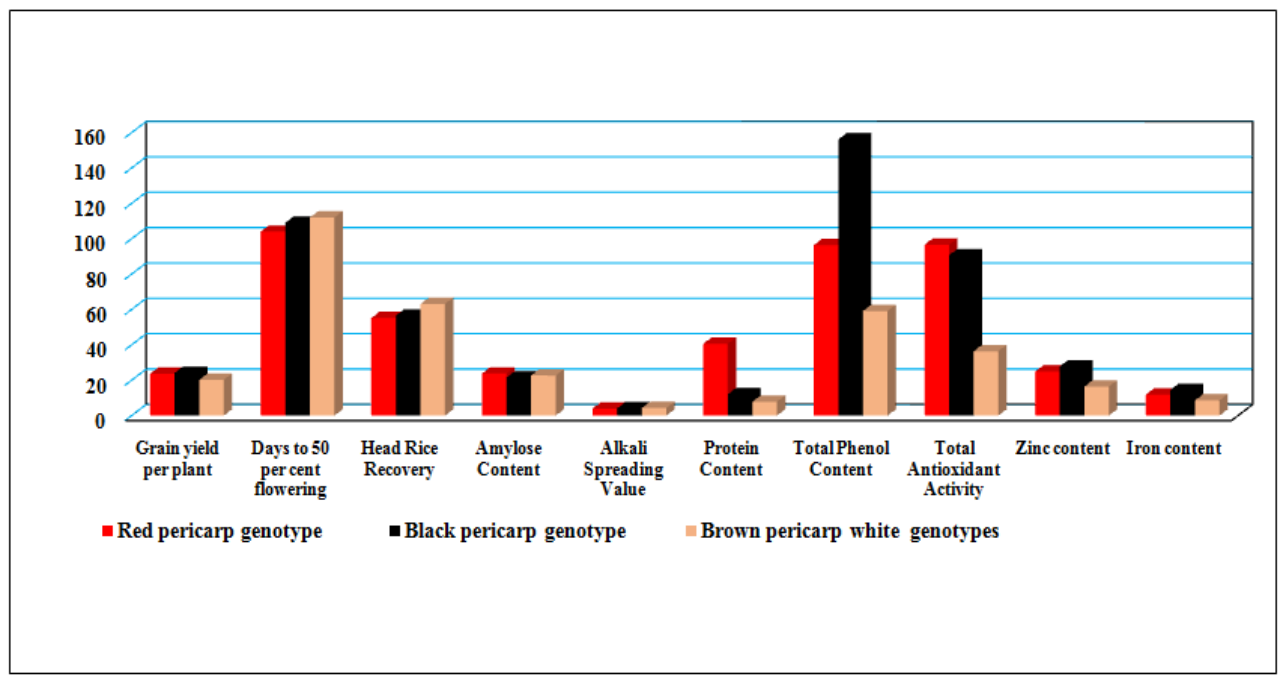

Fig.2 Performance of promising genotypes for important traits, in comparison to the check, BPT 5204

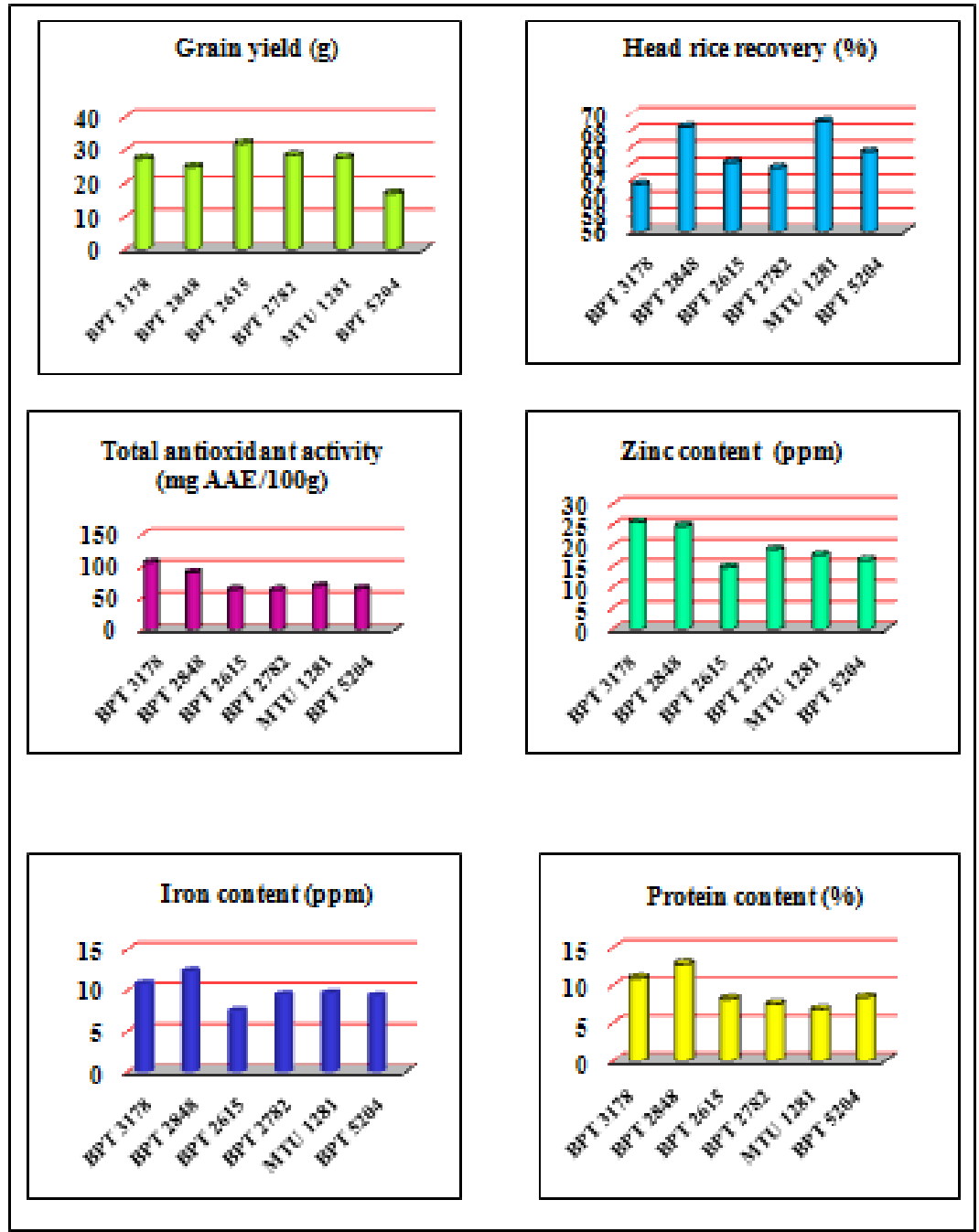


Plate.1 Red pericarp rice genotypes studied in the present investigation

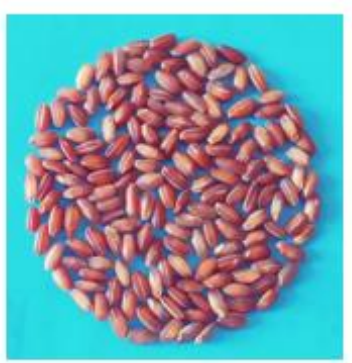

Asandi

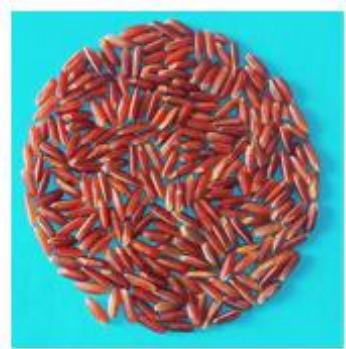

Apputhokal

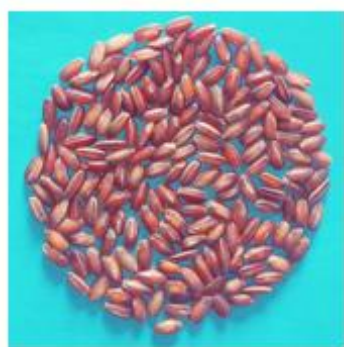

Chittiga

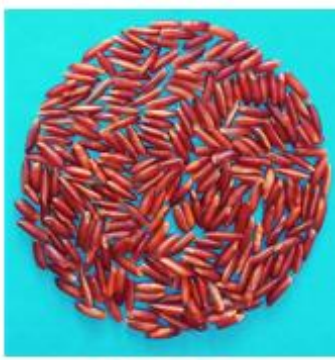

BPT 3111

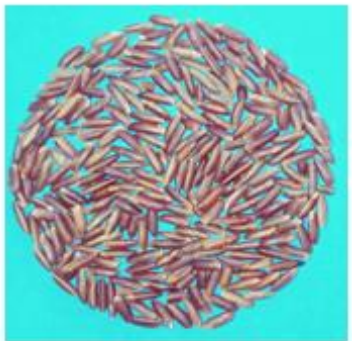

BPT 3139

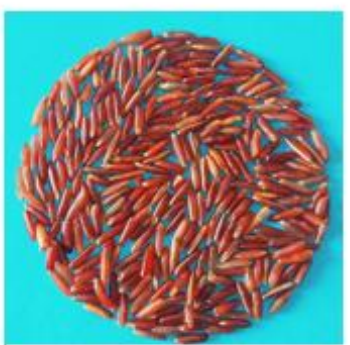

BPT 3178

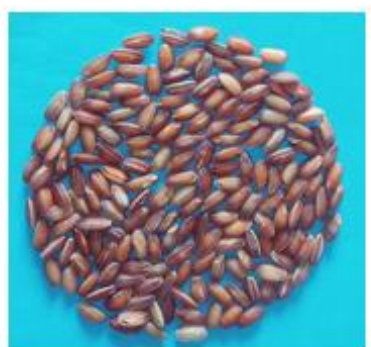

Hallahhatta

Plate.2 Black pericarp rice genotypes studied in the present investigation

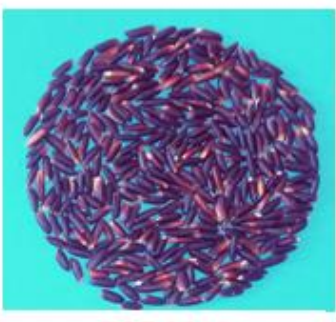

BPT 2841

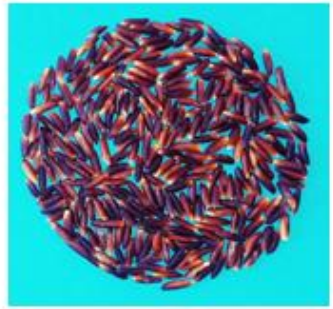

BPT 3141

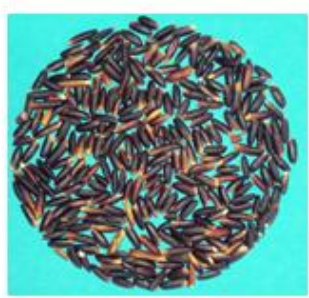

BPT 2848

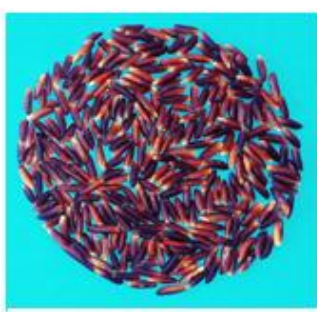

BPT 3145

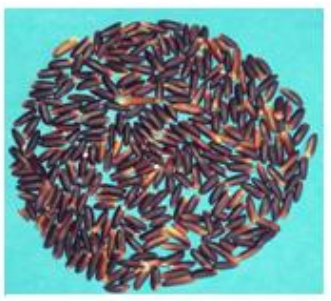

BPT 3136

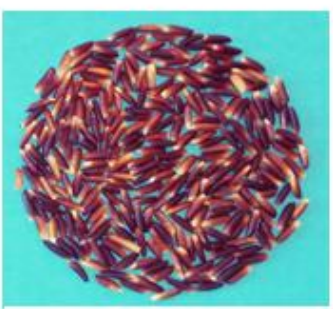

BPT 3165

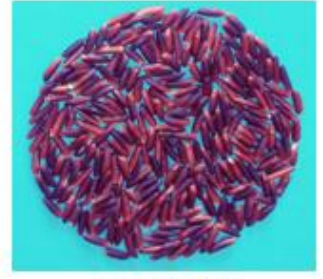

BPT 3140

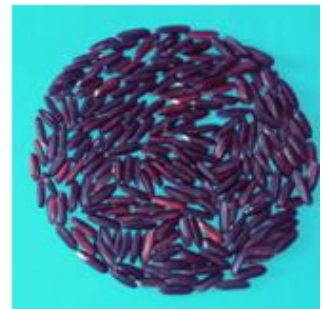

Kakirekalu 
Major nutritional problems in rice consuming countries comprise of malnutrition and deficiency of iron resulting in anaemia. Identification of a genotype with high iron content is therefore required. In the present study, iron content was noticed to range from 6.46ppm (BPT 2846) to $19.25 \mathrm{ppm}$ (BPT $3165)$. The overall mean iron content of the genotypes studied in the present investigation was $10.71 \mathrm{ppm}$. In general, the black pericarp genotypes recorded higher iron content (14.54ppm), compared to red pericarp $(11.84 \mathrm{ppm})$ and white rice $(8.56 \mathrm{ppm})$ genotypes. Raghuvanshi et al., (2017) and Pathak et al., (2017) also reported that pigmented rice was found to have high amount of iron content than non-pigmented rice. Among the black pericarp genotypes, BPT 2848 (12.33ppm) recorded minimum iron content, while BPT 3165 recorded maximum iron content (19.25ppm). Among the red pericarp genotypes, iron content was noticed to range from 10.76ppm (BPT 3178) to 13.33ppm (BPT 3139); and from 6.46ppm (BPT 2846) to 10.46 per cent (JKRH 3333) among the white rice genotypes. A perusal of the results revealed significantly greater iron content, compared to the check, BPT 5204 (9.30ppm) for all red and black pericarp genotypes studied; and none among the white rice genotypes studied.

The results revealed 23 genotypes of medium slender group, of which two were red pericarp genotypes (BPT 3111 and BPT 3139) and three black pericarp genotypes (BPT 2841, BPT 2848 and BPT 3145), while all the 18 white rice genotypes studied belonged to the medium slender group. Further, four red pericarp (Apputhokal, Asandi, Chiitiga and Hallabhatta) and two black pericarp genotypes (BPT 3136 and BPT 3141) recorded medium bold grain type, while one red pericarp (BPT 3178) and two black pericarp genotypes (BPT 3140 and BPT 3165) had recorded long slender grain type.
Only one black pericarp genotype (Kakirekalu) had recorded long bold grain type in the present study.

In general, the black pericarp genotypes studied were observed to be high yielding, with intermediate amylose content, high phenol, protein, zinc and iron content, compared to the red pericarp and white rice genotypes studied in the present investigation. The red pericarp genotypes were however, early with high antioxidant activity, compared to the black pericarp and white rice genotypes studied in the present investigation. Further, the red pericarp genotypes were also observed to possess intermediate amylose content in addition to relatively high total phenols, protein, zinc and iron content, compared to the white rice genotypes studied. The white rice genotypes, however, recorded higher head rice recovery per cent, in general, compared to the red and black pericarp genotypes. The findings are in broad agreement with the reports of Sridevi (2018).

Details of the promising slender grain genotypes with intermediate amylose content in addition to superiority over the check variety, BPT 5204, with more than 30 per cent higher grain yield, coupled with significantly higher levels of total antioxidant activity and zinc along with at least on par head rice recovery per cent, iron content and protein content are presented in Table 4 and Fig.2. The performance of these genotypes, as alternate to the popular rice variety, BPT 5204, needs to be evaluated across seasons and locations prior to their potential commercial exploitation as high yielding and nutritionally rich rice genotypes.

\section{References}

Chakuton, K., Pitag, D.P and Nakornriab, M. 2012. Phytochemical content and antioxidant activity of colored and non- 
colored Thai rice cultivars. Asian Journal of Plant Sciences. 11 (6): 285293.

$\mathrm{Hu}, \mathrm{C} .$, Zawistowski, J., Ling, W and Kitts, D.D. 2003. Black rice (Oryza sativa L. indica) pigmented fraction suppresses both reactive oxygen species and nitric oxide in chemical and biological model systems. Journal of Agriculture and Food Chemistry. 51: 5271-5277.

Irakli, M.N., Samanidou, V.F., Biliaderis, C.G and Papadoyannis, I.N. 2012. Simultaneous determination of phenolic acids and flavonoids in rice using solidphase extraction and RP-HPLC with photodiode array detection. Journal of Separation Science. 35: 1603-1611.

Itani, T and Ogawa, M. 2004. History and recent trends of red rice in Japan. Japanese Journal of Crop Science. 73 (2): 137-147.

Itani, T., Tamaki, M., Arai, E and Horino, T. 2002. Distribution of amylose, nitrogen and minerals in rice kernels with various characters. Journal of Agricultural and Food Chemistry. 50 (19): 5326-5332.

Laenoia, S., Chanakan, P.U.T., Dellc, B and Rerkasem, B. 2015. Iron and zinc variation along the grain length of different Thai rice varieties. ScienceAsia. 41: 386-391.

Meijuan, D and Samuel, S.M.N. 2005. Profiling the expression of genes controlling rice grain quality. Plant Molecular Biology. 59: 165-178.

Nagadurga Rao, N. 2019. Characterization of rice genotypes for distinctiveness, uniformity, stability and nutritional parameters. M.Sc (Ag.) Thesis. Acharya N.G. Ranga Agricultural University,
Guntur, India.

Panse, V.G and Sukhatme, P.V. 1967. Statistical Methods for Agricultural Workers. ICAR, New Delhi.103-108.

Pathak, K., Rahman, S.W., Bhagawati, S and Bhabesh, G. 2017. Assessment of nutritive and antioxidant properties of some indigenous pigmented hill rice (Oryza sativa L.) cultivars of Assam. Indian Journal of Agricultural Research. 51 (3): 214-220.

Raghuvanshi, R.S., Anuradha, D., Tiwari, D and Swetha, S. 2017. Qualitative characters of red rice and white rice procured from local market of Uttarakhand - a comparative study. Journal of Rice Research. 10 (1): 49-53.

Saikia, S., Dutta, H., Saikia, D and Mahanta, C.L. 2012. Quality characterization and estimation of phytochemicals content and antioxidant capacity of aromatic pigmented and non-pigmented rice varieties. Food Research International. 46: 334-340.

Sridevi, P. 2018. Variability for nutritional and biochemical quality parameters in colored rice genotypes (Oryza sativa L.). M.Sc (Ag.) Thesis. Acharya N.G. Ranga Agricultural University, Guntur, India.

Tian, S., Nakanura, K and Kayahara, H. 2004. Analysis of phenolic compounds in white rice brown rice and germinated brown rice. Journal of Agricultural and Food Chemistry. 52: 4808-4813.

Veni, B.K., Rao, C.V.R and Sandeep, R.D. 2016. Total phenol content and antioxidant activity in colored rice genotypes. IIRR Newsletter. 14: 2-3.

\section{How to cite this article:}

Kumar Saurabh Singh, Y. Suneetha, G. Vinay Kumar, V. Srinivasa Rao, D. Sandeep Raja and Srinivas, T. 2020. Evaluation of Coloured and White Rice Genotypes for Yield and Quality. Int.J.Curr.Microbiol.App.Sci. 9(07): 2454-2466. doi: https://doi.org/10.20546/ijcmas.2020.907.288 